\title{
SELECTION OF THE PATH OF THE EUPALINOS AQUEDUCT AT ANCIENT SAMOS ON THE BASIS OF GEODETICAND GEOLOGICAL / GEOTECHNICAL CRITERIA
}

\author{
Stiros S. ${ }^{1}$ and Kontogianni V. ${ }^{2}$ \\ ${ }^{1}$ University of Patras, Department of Civil Engineering, Laboratory of Geodesy and Geodetic Applications, \\ 26500 Patras, Greece, stiros@upatras.gr \\ ${ }^{2}$ Institute of Geology \& Mineral Exploration (IGME), Division of Engineering Geology, \\ 13677 Acharne, Greece, villy@igme.gr
}

\begin{abstract}
The tunnel of Eupalinos at Samos (Greece) is certainly one of the most admirable works in antiquity, but several questions concerning its plan, and especially the selection of its path, leading to an 'S' type curve, a longer tunnel and a longer aqueduct remain without an answer. In this paper we try to provide an answer to the question 'why Eypalinos selected the specific path for the aqueduct?' on the basis of geotechnical and geodetic evidence.

Two basic criteria should have been satisfied for the tunnel planning: first, that it had to be excavated through rocks with mechanical properties suitable for a safe underground excavation, and second, that the portals should have been in areas permitting accurate geodetic orientation and guidance of the excavation.

The overall selection of the tunnel path indicates that Eupalinos had an excellent understanding of the theory of errors and an ability for geological and geotechnical evaluation of the mechanical characteristics of the ground, i.e. a primitive system of the rock strength classification, with remarkable similarities with the modern GSI method.
\end{abstract}

Key words: Aqueduct, Geodesy, GSI, Tunnel.

\section{Introduction}

The Eupalinos Tunnel was constructed as part of an aqueduct to provide water to the town of Samos (eastern Aegean Sea) in circa 530BC (Figs. 1 and 2). This tunnel, more than 1000m long, is the first tunnel known to be excavated from both portals using strict geotechnical and geodetic techniques. It was functional for about 1000 years, but subsequently blocked, buried and forgotten for about 1500 years. It was found in the late 1800 's, following the precise description of Herodotus, a $5^{\text {th }} \mathrm{c}$. BC historian, in an effort to provide water to the town of Samos.

The whole aqueduct system consists of three parts, with the tunnel representing its middle part (see Fig. 3). The northern segment, $\sim 895 \mathrm{~m}$ long, between the spring and the northern tunnel portal consists of a buried channel ('cut-and-cover') and a qanat (a channel excavated at the bottom of wells, see Stiros, 2009a), while the southern part, from the southern tunnel portal to the town cistern, $\sim 620 \mathrm{~m}$ long, consists of a qanat. Although the aqueduct, and especially the tunnel, have been recognized as a masterpiece of engineering at several studies - culminating with the publication of a volume by Kienast (1995) - there are still some questions concerning its overall design. 

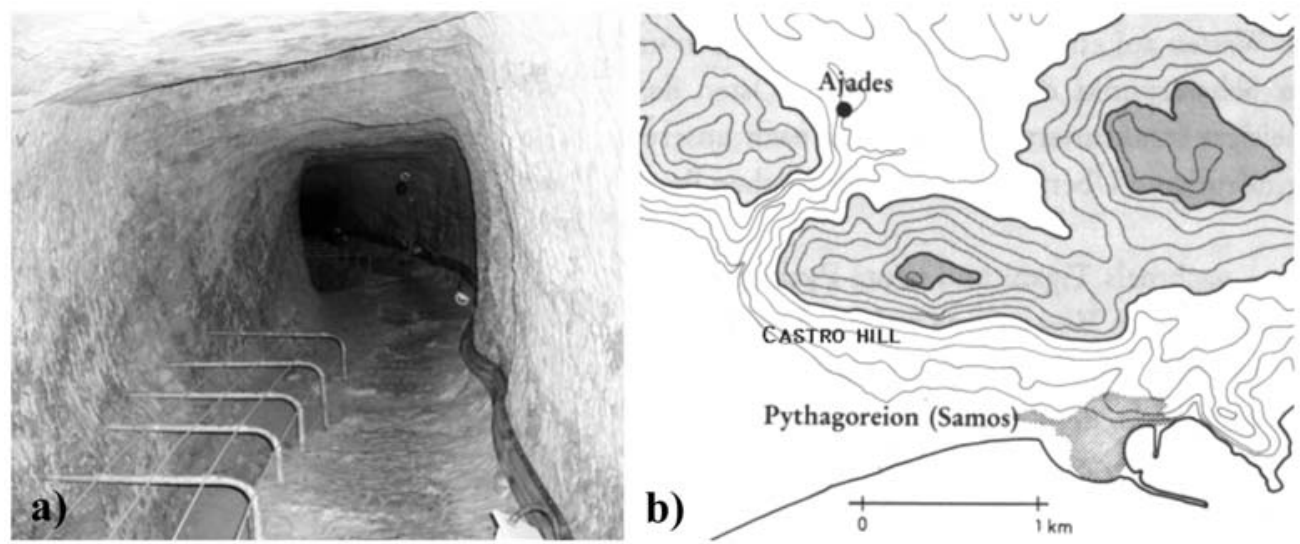

Fig. 1: (a): Inside view of the Eupalinos tunnel (b): Topography in the Eupalinos tunnel area. The aqueduct provides water from the Ajades Spring to the Samos town (modern Pythagoreion) cutting through the Castro Hill.

A main question concerns the selection of the overall aqueduct path. Since it was argued by Kienast (1995) and previous investigators that a main constraint for the tunnel was the need to bring water at the maximum possible elevation, an aqueduct of minimum length, approximately along a straight line would be required.

Such a hypothetical aqueduct would have been only $1500 \mathrm{~m}$ long, i.e. $1 \mathrm{~km}$ shorter than the constructed one, and apart from the fact that it would deliver water at a level about $2 \mathrm{~m}$ higher, it would correspond to a less expensive and less time-consuming project. In addition, it would obviously correspond to a lower-cost and shorter-duration project.

Still, Eupalinos, the chief engineer, selected a longer, curved path delivering water at a lower elevation. Which were the reasons for the selection of a specific route and rejection of other alternatives?

In a previous article (Stiros 2009a) it was shown on the basis of geodetic evidence that the tunnel path selected by Eupalinos represented one of the two possibilities: the selected path and the alternative path \#3 (see Fig. 3). In this article we examine the possible reasons for the selection of the overall aqueduct path, and conclude that this selection was dictated by the local geological and geotechnical conditions. This indicates that even in the $6^{\text {th }} \mathrm{c}$. BC Eupalinos was aware of the variations of geological strength of rocks, and probably he was successfully applying a primitive but effective rock strength classification system, in principle not very different from those used in our days (for instance the GSI classification system, Hoek and Brown, 1997; Marinos and Hoek, 2000).

\section{Possible alternative routes for the Samos aqueduct}

Figure 3 summarizes the existing path of the Samos aqueduct plus three alternative routes. Among them routes \#1 and \#2 were proposed or summarized by Kienast (1995), while \#3 was examined by Stiros (2009a). It is astonishing that the selected route corresponds to the longer tunnel (approximately $1040 \mathrm{~m}$ ) and the longer overall aqueduct (1515m). Alternative tunnel \#1 would lead to a tunnel of nearly equal length but to a shorter aqueduct, avoiding an about $200 \mathrm{~m}$ long qanat. Alternative tunnel \#2 would lead to an about $925 \mathrm{~m}$ long tunnel but a longer overall aqueduct ( $400 \mathrm{~m}$ longer), while alternative tunnel \#3 would lead to a less than $900 \mathrm{~m}$ long tunnel and a minimum aqueduct length, since section 4-5 could have been constructed as a qanat. 


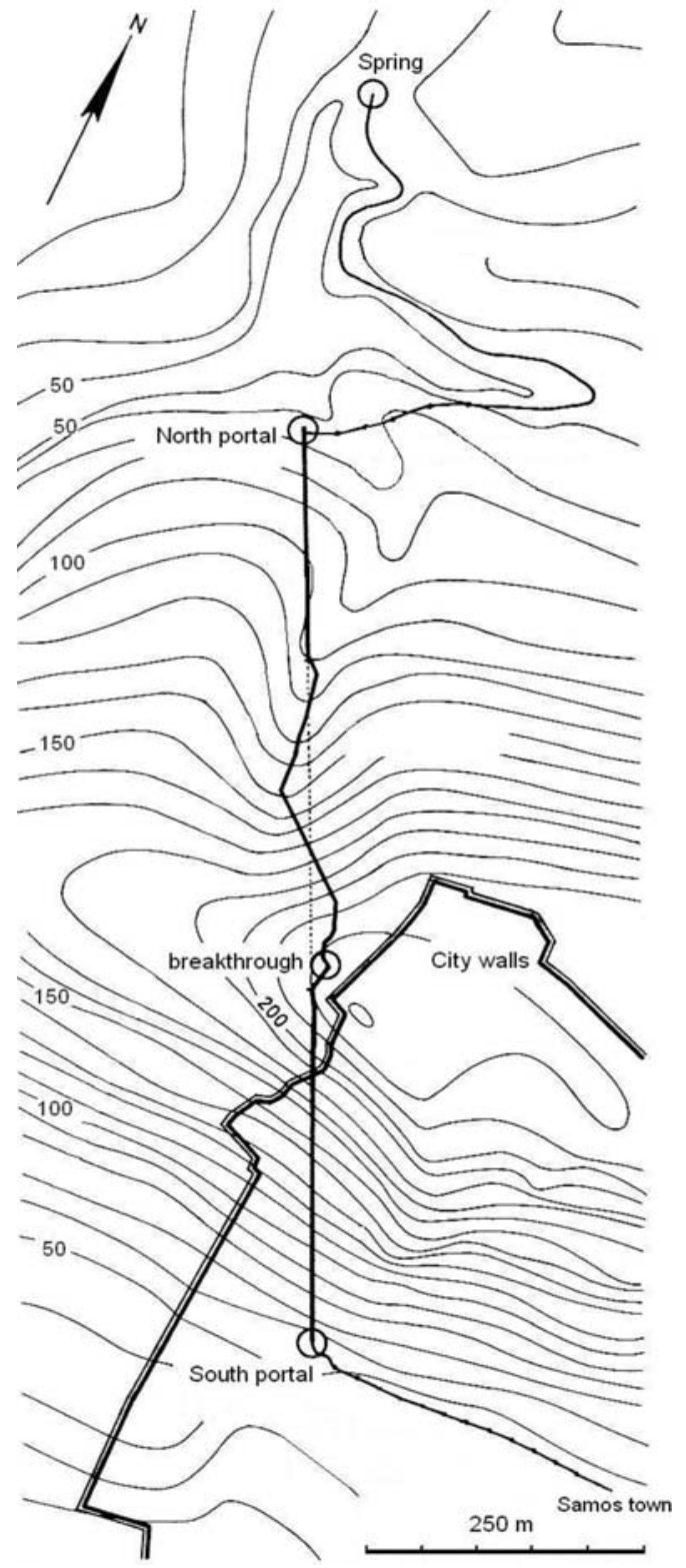

Fig. 2: Plan of the ancient Samos aqueduct, consisting of three segments: (a) a channel bringing water from the spring to the northern tunnel entrance (portal), (b) the tunnel and (c) a channel conveying water from the southern tunnel portal to a main cistern in the Samos Town (after Kienast, 1995).

Selection of the aqueduct route would be easily explained if a long aqueduct was combined with a short tunnel, given that the latter represents the most difficult, time consuming and expensive part of the project, and represented an innovative engineering practice at the time. In fact, the Samos tunnel was the first tunnel ever constructed from two portals using strict geodetic techniques, while qanats or buried channels (“cut-and-cover') were quite usual in antiquity (Grewe, 1998; Stiros, 2009b). Still, the selected aqueduct path corresponds to the maximum possible tunnel length, $>1040 \mathrm{~m}$, in comparison to alternatives as low as 930m (\#2) or even <900m (\#3) (see Fig. 3)! 


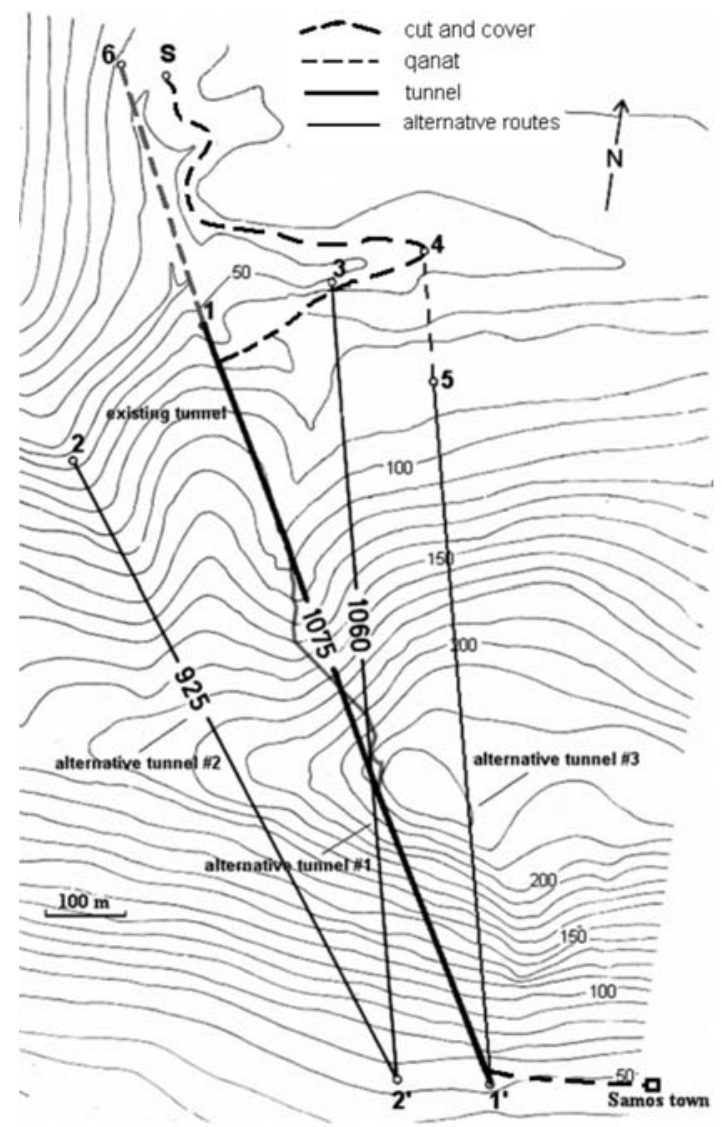

Fig. 3: Plan view of the Eupalinos tunnel and of the three alternative paths of shorter length. Partly after Kienast (1995).

\section{Rationale for the aqueduct path selection}

Discarding the possibility of an intentional construction of a longer aqueduct either for draining more money for the construction or as a matter of proud (a tunnel superior to any other existing), we can think of the following possible reasons for the aqueduct path selection:

First, a survey gross error. This explanation can readily be rejected, given that Eupalinos proved able to align a tunnel opened from two portals.

Second, technical constraints, in particular geodetic and geotechnical. Geodetic constraints are important for the safe orientation and guidance of a tunnel opened from two portals even for modern tunnels (Kontogianni, 2005, Stiros, 2009b), while geotechnical data constraint a tunnel cutting through rocks that can easily excavated without causing stability problems and require costly and time-consuming support measures. This seems to be the only reasonable explanation.

In fact, Stiros (2009a) noticed that on the grounds of geodesy there were only few alternative paths for the tunnel fulfilling the requirement of long baselines in free spaces at the two portals. Such baselines are absolutely necessary for the geodetic orientation and guidance of the excavations.

The problem of geotechnical constraints is for the first time examined in this paper, although the geology along the tunnel path have been studied by other investigators as well (see Kienast, 1995). 


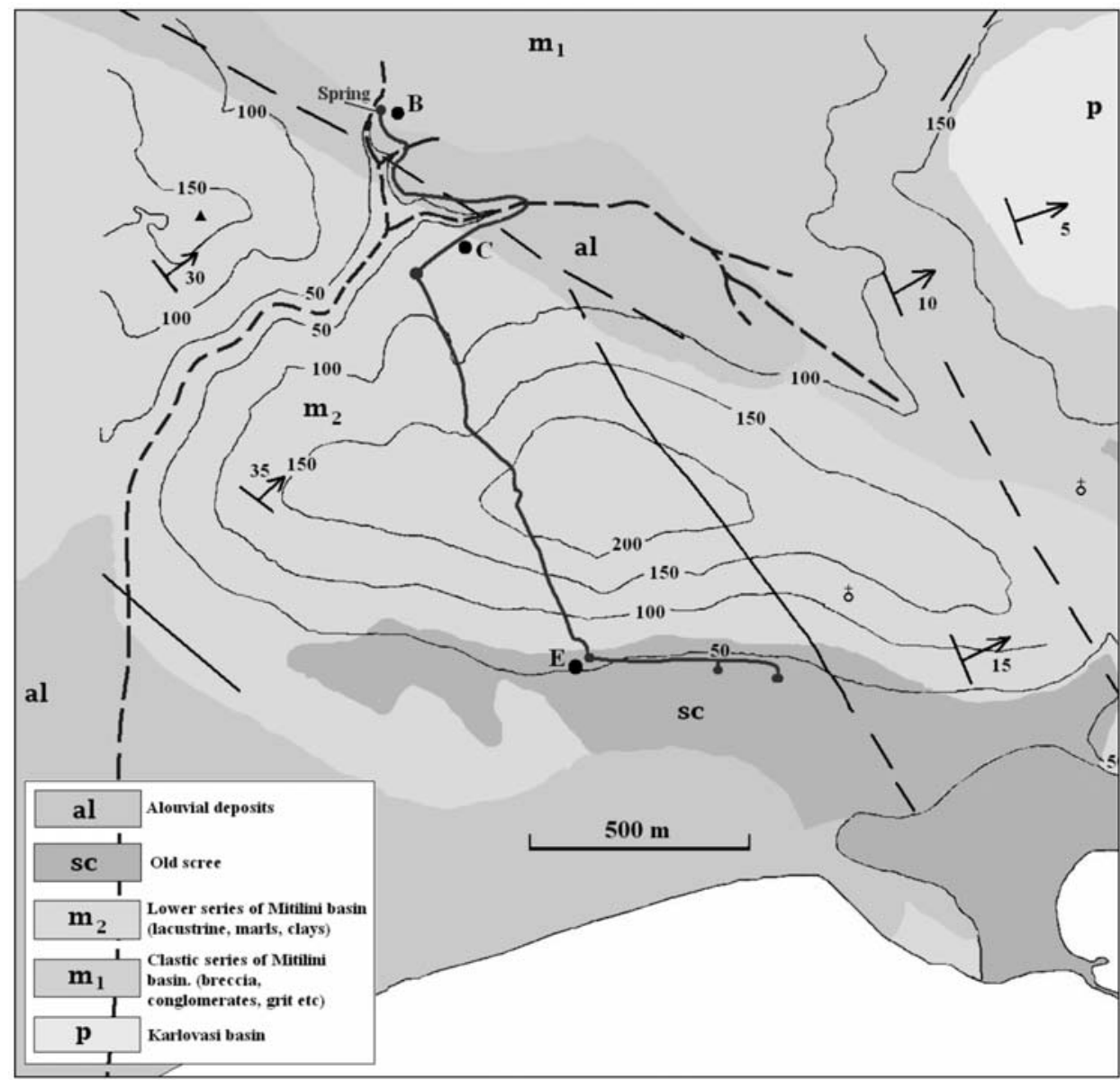

Fig. 4: The geology of the area consists of a NE-dipping monocline incised by a stream leading from the Ayades spring to the sea (simplified after Theodopoulos, 1979). GSI values are reported for locations B, C and E.

\section{Geological and geotechnical characteristics of the aqueduct area}

The morphology of the area is dominated by the Castro hill, $200 \mathrm{~m}$ high, and an incised valley through which the Ayades spring is discharged to the sea (Fig. 4). The geology of the Castro hill corssed by the tunnel, is rather simple, and consists of the Lower series of the Mytilini formation, lacustrine medium to thick-bedded travertine-type limestones strata, forming a monocline tilted $30^{\circ}$ $\mathrm{N}$ on the average. Near the Ayades spring, geologic formations consist of clastic series of the Mytilini basin (Pontian), fluvio-lacustrine deposits consisting of alternating beds of breccia, conglomerates, sandy marls and marly limestones, with intercalations of travertine limestones. At the south portal of the tunnel strongly cemented old scree and talus cones are found (Fig. 4).

The incised valley through which the Ayades spring is discharged to the sea cuts the monocline dominating the geology of the area and permits an easy understanding of the stratigraphy of the tunnel area in a natural section; additional observations can be made in ancient quarries near the $150 \mathrm{~m}$ high peak, at the NW part of the map. 
A careful field study permitted to understand the structure of the area around the tunnel, as well as the geotechnical characteristics of the rocks.

First, it was found that the strength of the rocks of the sequence of the Kasto hill decreases upwards, and since this represents a monocline, strong rocks are found near the south portal and weak rocks near the Ayades spring.

Second, we tried to find a measure of the strength of these rocks adopting the Geological Strength Index (GSI) classification (Hoek and Brown, 1997), which has been widely used in Greece (Marinos and Hoek, 2000). Using the typical GSI criteria, we estimated the GSI index for rocks in several representative areas and summarized these results in Table 1.

Table 1. GSI values of rocks for selected locations (see Fig. 4) near the Samos tunnel.

\begin{tabular}{|c|c|}
\hline Location & GSI \\
\hline B & $35-40$ \\
\hline C & $30-40$, locally $<20$ \\
\hline E & $80-90$ \\
\hline
\end{tabular}

Third, it is evident that the results of the geotechnical (GSI) approach is consistent with the results of the structural/geological study, and hence it puts some constraints to the selection of the tunnel path: The area around point $\mathrm{C}$ was not suitable for tunnel construction in antiquity (low strength rocks), and the north portal should have been shifted to the SW. This is schematically shown in Figure 5.

\section{Constraints for the tunnel path selection}

Previous discussion reveals that Eupalinos had to reject any plans for a tunnel near point $\mathrm{C}$ (incompetent rocks, unsafe excavation); in order to meet competent rocks he had to shift the north tunnel portal as long as possible to the SW, for instance till path \#3 in Figure 3. This would lead to a $>10 \%$ shorter tunnel (see Fig. 3), and this advantage would counteract any problems caused by a longer aqueduct.

Still, Eupalinos selected an intermediate solution, fixing the north portal at the boundary between weak and relatively strong rocks. For this reason he had to support a part of the tunnel, and this support was extended in Roman times (Kienast, 1995).

What are the characteristics of this path? As Stiros (2009a) noticed, free space to fix a long survey base line necessary for the orientation of the tunnel and guidance of its excavation exists only at the extension of the selected tunnel path (see Fig. 3). In all points farther SW, where lithological conditions are more favourable, the incised stream does not permit fixing any long baseline. Since the length of such a baseline was critical for the success of the tunnel orientation, Eupalinos had to make a compromise between geodetic requirements and geotechnical requirements. The selected path proved that his overall rationale was correct, and this proves an excellent under- 


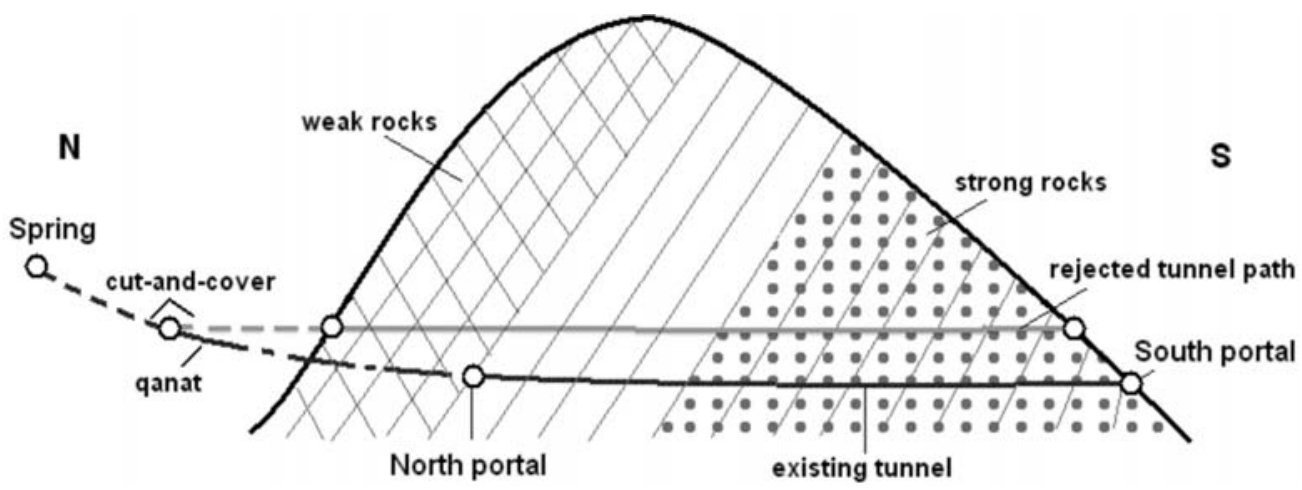

Fig. 5: Sketch of the longitudinal section of the Castro hill along the Ayades stream. Competent rocks are found in the lower parts of the sequence and non-competent in its upper parts, close to point C in Fig. 4. Superimposed on this sketch are the approximate tunnel path \#3 (rejected) and the tunnel path selected by Eupalinos. It is obvious that the criterion for the path selection was the strength of rocks in the north portal.

standing of the geodetic requirements for such a magnificent project and of the geology and of rock strength conditions. The latter required a detailed understanding of the rock mass strength characteristics, permitting comparisons between rocks of different types, and obviously costly decisions. Most probably a primitive Geologic Strength Index was used for this task.

\section{Conclusions}

Planning of the Eupalinos tunnel path was definitely far from being a random choice. All available data indicate that the path was selected as a compromise between the geotechnical and the geodetic design. Eupalinos had at least an excellent empirical understanding of the geology and an ability for characterization of the rock mass quality, reminiscent of the modern rock mass classification systems such as GSI, as well as an excellent understanding of the techniques, requirements and limitations for alignment and guidance of underground excavations. Without such knowledge it would be absolutely impossible to complete such as demanding project.

\section{References}

Grewe, K., 1998. Licht am Ende des Tunnels. Plannung und Trassierung im antiken Tunnlebau. Verlag Philip von Zabern, Mainz am Rhein, 218 pp.

Hoek, E. and Brown, E. T. (1997). Practical estimates of rock mass strength. Int. J.Rock Mech. Min. Sci., 34 (8), 1165-1186.

Kienast, H., 1995. Die Wasserleitung des Eupalinos auf Samos. Deutsches Archaeologisches Institut, Samos Band XIX.

Kontogianni, V., 2005. Geodetic monitoring of tunnel deformation: methodology assessment and data analysis. Dept. of Civil Engn, Patras University, Greece.

Marinos, P. and Hoek, E., 2000. GSI: A Geologically Friendly Tool for Rock Mass Strength Estimation. International Conference on Geotechnical \& Geological Engineering (GeoEng 2000), Technomic 
Publ., 1422-1442, Melbourne.

Stiros, S., 2009a. Orientation and alignment of the 5th c. BC tunnel of Eupalinos at Samos (Greece). Survey Review, 41, 313, 218-225.

Stiros, S., 2009b. Alignment and breakthrough errors in tunnelling, Tunnelling and Underground Space Technology, 24, 236-244.

Theodoropoulos D., 1979. Geological Map of Samos. 1:50,000 scale. Institute of Geology and Mineral Exploration (IGME), Athens. 
